\title{
Programa Ciclovía do Instituto Distrital de Recreación y Deporte (IDRD) - Bogotá, Colômbia
}

\author{
Ciclovía Program of the Instituto Distrital de Recreación y Deporte (IDRD) - Bogotá, Colombia \\ Programa Ciclovía del Instituto Distrital de Recreación y Deporte (IDRD) - Bogotá, Colombia \\ LEANDRo DRi MANFIOLETE Troncoso ${ }^{1}$ \\ Universidad Austral de Chile, UACh, Valdivia, Chile
}

\begin{abstract}
RESUMO
O objetivo do artigo foi compreender o fenômeno social ciclismo urbano como uma estratégia de política pública para o planejamento de cidades. Entrevistamos uma pessoa que foi, durante dez anos (2003-2013), coordenadorgeral do Programa Ciclovía do Instituto Distrital de Recreación y Deporte (IDRD) - Bogotá, Colômbia. Seguiuse a abordagem fenomenológico-hermenêutica para a análise descritiva do conteúdo da entrevista na perspectiva teórica da governamentalidade (Michel Foucault). Consideramos que, a participação social, a gestão da política pública e a organização institucional são aspectos fundamentais para o sucesso das atividades do Programa Ciclovía que, ao congregar todos os finais de semana parcela significativa da população desta metrópole, está orientado para executar ações normativas direcionadas para a promoção da saúde e prevenção de doenças crônico-degenerativas através do uso de bicicleta em ciclovias recreativas.
\end{abstract}

Palavras-chave: Ciclismo. Política Pública. Planejamento de Cidades.

\begin{abstract}
The objective this article was to understanding social phenomenon urban cycling as a public policy strategy for city planning. We interviewed a general coordinator for ten years (2003-2013) of Programa Ciclovía, Instituto Distrital de Recreación Deporte (IDRD) - Bogotá, Colombia. The phenomenological-hermeneutic approach followed descriptive analysis of content interview in relation to the theoretical perspective of governmentality (Michel Foucault). We consider that social participation, public policy management and institutional organization are fundamental aspects for the success of Programa Ciclovía, activities that congregates every weekend a significant part of the population of this metropolis that is oriented to execute normative actions directed to health promotion and prevention of chronic-degenerative diseases through learning use of cycling recreational cycle paths.
\end{abstract}

Keywords: Cycling. Public Policy. City Planning.

\section{RESUMEN}

El objetivo del artículo fue la comprensión del fenómeno social del ciclismo urbano como una estrategia de política pública para la planificación de ciudades. Entrevistamos a un coordinador general durante diez años (2003-2013) del Programa Ciclovía del Instituto Distrital de Recreación y Deporte (IDRD) - Bogotá, Colombia. Se siguió el enfoque fenomenológico-hermenéutico para el análisis descriptivo del contenido de la entrevista con la perspectiva teórica gubernamentalidad (Michel Foucault). Consideramos que, la participación social, la gestión de la política pública y la organización institucional son aspectos fundamentales para el éxito de las actividades del Programa Ciclovía que, congrega todos los fines de semana parte significativa de la población de esta metrópolis, está orientado a ejecutar acciones normativas dirigidas para promoción de la salud y prevención de enfermedades crónico-degenerativas a través del uso de la bicicleta en ciclovías recreativas.

Palabras clave: Ciclismo. Política Pública. Planificación de Ciudades.

\footnotetext{
1 Doutorando em Ciências Humanas (Mención Discurso y Cultura) pela UACh. E-mail: leandro_dri@hotmail.com
} 


\section{INTRODUÇÃOO}

O ciclismo urbano como estratégia de política pública busca alcançar os Objetivos do Desenvolvimento Sustentável (ODS) (ONU, 2015). Nas 17 diretrizes delineadas pela Organização das Nações Unidas (ONU), a mobilidade ativa sustentável por bicicleta caracteriza-se, de acordo com o Relatório Mundial das Cidades (HABITAT III) por ser uma alternativa viável ao design de cidades voltadas à escala humana reforçada (ONU, 2016). Nesse sentido, diante da mudança climática apresentada na Conferência Mundial do Clima (COP-21) (ONU, 2015) agravada com o consumo acelerado dos recursos naturais, principalmente com a exploração de petróleo que abastece o sistema de transporte motorizado, esta forma de desenvolvimento humano urbano tem gerado um quadro estrutural de obesidade e sedentarismo (PAHO, 2007) causador de doenças crônico-degenerativas (WHO, 2018).

No Brasil, ações governamentais têm buscado valorizar o planejamento urbano voltado para a mobilidade ativa por bicicleta: o Estatuto das Cidades (BRASIL, 2008) legislação que orienta os municípios na elaboração do Plano Diretor Estratégico, na Política Nacional de Mobilidade Urbana (BRASIL, 2012a), na Política Nacional de Promoção da Saúde (BRASIL, 2014), no Caderno para Elaboração dos Planos de Mobilidade Urbana (BRASIL, 2015) e no Programa Bicicleta Brasil (PBB) (BRASIL, 2018). Também ações não-governamentais são fonte de debate acadêmico sobre a economia da bicicleta no Brasil (ANDRADE; RODRIGUES, 2018), no desenvolvimento latino-americano (BAUMANN et al., 2013) e europeu (GODEFROOIJ et al., 2009), mas também de reivindicações dos movimentos sociais cicloativistas como o Foro Mundial de la Bicicleta (FMB, 2018), a Liga dos Ciclistas Americanos (EUA) (MCLEOD, 2016) e a Federação dos Ciclistas Europeus (NEUN; HAUBOLD, 2016).

Apesar do risco de se pedalar nas vias públicas com padrões determinantes que favorecem acidentes de trânsito com ciclistas (HARTOG et al., 2011), o apoio institucional à mobilidade ativa sustentável deve ser encarada como uma possibilidade de intervenção para a promoção de atividade física e social (TORRES et al., 2013) com efeitos diretos na saúde pública (CARVALHO; FREITAS, 2012), cabendo ao poder público a responsabilidade de organizar e executar programas que incentivem o uso equitativo do espaço público (FAJERSZTAJN et al., 2016; SPERANDIO; FRANCISCO FILHO; MATTOS, 2016).

Um exemplo de ação governamental bem sucedida na promoção do ciclismo urbano é do Distrito Central de Bogotá, Colômbia que, de acordo com a Secretaría Distrital de Movilidad, em 2015, dos mais de 17 milhões de deslocamentos diários, 845 mil foram realizados por ciclistas, o que corresponde a $5 \%$ dos deslocamentos (ALCADÍA MAYOR DE BOGOTÁ, 2015). Para efeito de comparação no território brasileiro, na cidade de São Paulo a estimativa é de $2 \%$ dos deslocamentos diários realizados por bicicleta (CICLOCIDADE, 2016). Uma parte do sucesso da referida administração, está no Instituto Distrital de Recreación y Deporte (IDRD), unidade gestora que, inspirada no conceito "ciclovías Recreativas" (ESTRADA et al., 2009), organiza e executa o Programa Ciclovía, uma política de Estado reconhecida em nível mundial pela rede $\mathrm{C}-40$ de megacidades comprometidas em lidar com as mudanças climáticas.

O objetivo do artigo foi compreender o Programa Ciclovía como uma estratégia de política pública para o planejamento de cidades. 


\section{Metodologia}

No contexto do movimento social cicloativista, essa experiência esteve situada a uma viagem de bicicleta entre os Departamentos de Antioquia (Medellín) e Cundinamarca (Bogotá) na realização de entrevistas com pessoas ligadas à cultura de bicicleta, dentre elas: professores universitários, ex-atleta de ciclismo de estrada de renome internacional, mecânicos de bicicleta, cicloativistas e gestores públicos onde foi selecionada a entrevista realizada com Jorge Maurício Ramos Martínez, coordenadorgeral (período 2003-2013) do Programa Ciclovía do IDRD na gestão administrativa de atividades físico-recreativas com o fechamento parcial temporário (domingos e feriados das 7:00 às 14:00) de 121 quilômetros de vias públicas para o tráfego motorizado.

Quanto aos procedimentos metodológicos, seguiu-se a abordagem fenomenológica-hermenêutica (HENRY, 2010). Foi empregada a técnica de entrevista semiestruturada com a finalidade de estabelecer uma interação dialógica daquele que vivenciou a experiência (DENZIN; LINCOLN, 2015). Nesse sentido, emerge a noção de epoché como princípio metodológico com a suspensão das preconcepções através da redução fenomenológica para compreender a dinâmica discursiva ante uma atitude reflexiva do pesquisador que participou ativamente do processo pedagógico de investigação (VAN MANNEN, 2016).

Para descrição analítica do conteúdo da entrevista, empregamos o conceito governamentalidade (Michel Foucault) que, ao interpretarmos dentre um conjunto de práticas governamentais distribuídas pelo território da cidade de Bogotá focadas essencialmente para a população, está caracterizada uma racionalidade política de planejamento urbano condutora dos indivíduos por meio de tecnologias sociais:

\footnotetext{
A noção de governamentalidade é concebida como sendo o conjunto constituído pelas instituições, procedimentos, análises, reflexões, cálculos e táticas que permitem exercer especificamente, embora de forma complexa, o poder que tem por alvo principal a população, como forma de saber a economia política e por instrumento técnico essencial, os dispositivos de segurança. Como uma linha de força, concerne a tendência que, em todo o ocidente, não parou de conduzir a preeminência deste tipo de poder chamado "governo" sobre todos os outros - soberania e disciplina - trazendo por um lado, o desenvolvimento de toda uma série de aparelhos específicos de governo [e, por outro lado], o desenvolvimento de toda uma série de saberes (FOUCAULT, 2008, p. 144).
}

O encontro foi realizado no dia 12 de novembro de 2015 no local de trabalho do entrevistado com a entrevista gravada e traduzida do espanhol para o português. $O$ processo foi registrado na Plataforma Brasil, comprovante 029413/2015, parecer 1.202.636, submetido ao Comité de Ética e Pesquisa do Instituto de Biociências de Rio Claro, Universidade Estadual Paulista "Júlio de Mesquita Filho" (IBRC-UNESP), data 27/03/2015, registro CAAE: 43889115.1.0000.5465, resolução 466/12 do Conselho Nacional de Saúde (BRASIL, 2012b).

\section{RESUltados}

Durante a análise da entrevista, as categorias temáticas: a) Participação social; b) Gestão da política pública; c) Organização institucional, foram operadoras no processo de implantação das ciclovias recreativas em Bogotá. Certamente que, essas três categorias encontram-se imbricadas no discurso do entrevistado de tal modo que as 
narramos de forma entrelaçadas. Maurício Martinez relata seu envolvimento com a bicicleta até o momento de trabalhar como servidor público:

\begin{abstract}
A bicicleta entrou na minha infância quando aprendi a montar em uma bicicross aos sete anos. Aos quinze anos, meu pai presenteou com uma bicicleta de estrada que a utilizei por dois anos em competições. Atualmente, meus familiares saem para pedalar em grupo de 15 a 20 pessoas aos finais de semana com os pais levando seus filhos onde tenho levado o meu de 10 anos que gosta da bicicleta e já faz percursos de 50 quilômetros. Também aprecio a bicicleta em relação ao trabalho desde 1995 quando fui convidado para a coordenação desportiva do IDRD.
\end{abstract}

De sua experiência pessoal, Maurício Martinez descreve a sua capacidade como agente cultural em participar na organização de um projeto global para a sociedade colombiana. Ressaltamos a criação institucional do IDRD em 1978, considerado um estabelecimento público descentralizado, com personalidade jurídica, autonomia administrativa e patrimônio independente e titularidade administrada pelo Fondo Rotatorio de Espectáculos Públicos ligado a Secretaría de Cultura, Recreación y Deporte (ALCADÍA MAYOR DE BOGOTÁ, 2019a).

Após Maurício Martinez atuar na coordenação desportiva em diversas localidades da metrópole, sua experiência o conduz ao Programa Ciclovía:

De 2003 até 2013, ocupei a função administrativa de coordenador geral do Programa Ciclovía que objetiva fechar vias públicas da cidade para uso coletivo de bicicletas e pedestres, composto de um parque linear de 121 quilômetros de forma contínua com o serviço ofertado das 7h00-14h00 aos domingos e feriados ao longo do ano. A iniciativa está consolidada como política de Estado, embora nos primeiros anos tivessem ocorrido conflitos de reconhecimento à nível político, atualmente não há contraposições dos governantes porque o programa se transformou em uma iniciativa popular com mais de 1 milhão de pessoas por evento.

Historicamente, o Programa Ciclovía surge no dia 15 de dezembro de 1974 denominado "Mitin a favor de la bici", iniciativa conjunta entre a organização nãogovernamental "Pro-cicla" e o Departamento de Trânsito. Diante do sucesso da iniciativa, os promotores envolvidos passaram a contar com influência política para fechamento temporário do tráfego, o que gerou a promulgação em 1976 de "Las Ciclovías", porém, até 1994, as atividades eram realizadas intermitentemente por falta de suporte administrativo e programático (PARDO et al., 2011).

Em 1995, o político Antanas Mockus assume o Distrito Central em um contexto de violência urbana e, para enfrentar essa problemática, passa a difundir a "cultura ciudadana" como estratégia de incentivo à apropriação do espaço público na articulação entre instituições públicas e privadas para manutenção e ocupação destes lugares. Ao realizar mudanças administrativas no IDRD para gestão do Programa Ciclovía, o referido mandatário fomentou estas colaborações para suplementar o orçamento limitado da agência na introdução do sistema de voluntariado, o que acabou por expandir o número de empregados (MONTERO, 2017). Maurício Martinez entende que a parceria com o setor privado potencializou a disponibilidade de recursos humanos e financeiros colaborando para otimizar o desenvolvimento das atividades:

Como autoridade administrativa competente de controle do tráfego viário para gestão das vias públicas, organizamos eventos culturais e desportivos mediante regras e treinamento para não atrapalhar os frequentadores. $\mathrm{O}$ Programa Ciclovía encontra-se em renovação com um quadro de 


\begin{abstract}
funcionários formado por estudantes universitários contratados e/ou na condição de estagiários com renda que os ajuda na manutenção dos estudos. Para o desenvolvimento da gestão participativa, estabelecemos a figura Guardianes de la Ciclovía na função de orientar usuários transformando a via pública em um local de encontro seguro. Outra invenção foram os ciclopatrulleros em aliança com a Secretaria de Educación com os adolescentes cumprindo 120 horas de serviço à comunidade nos dois últimos anos do colégio. Atualmente são mais de mil servidores sociais treinados com uniforme próprio para trabalhar com recursos advindos em parceria públicoprivada não gerando custos para a administração pública, o que influencia a imagem institucional.
\end{abstract}

Desde 1997, o Programa Ciclovía consta de um quadro de funcionários formado por: um coordenador(a) geral, cinco coordenadores técnicos, 20 coordenadores operativos, 200 promotores, 40 guardianes de la ciclovía, professores de atividade física do Programa Recreovía (ALCADÍA MAYOR DE BOGOTÁ, 2019b), além de contar com um corpo de trabalho de 450 auxiliares de Polícias e 500 servidores do sistema de voluntariado criado para treinamento, execução e certificação (ALCADÍA MAYOR DE BOGOTÁ, 2019c).

No ano de 1998, o político Enrique Peñalosa assume o Distrito Central com foco em investimentos na construção de parques públicos, expansão da infraestrutura cicloviária, o que impulsionou o Programa Ciclovía no aumento das horas de funcionamento, conexão entre parques públicos, ou seja, foram ações caracterizadas como tecnologias de governo na promoção de práticas educativas e de cidadania visto no célebre slogan "Bogotá no tiene mar pero tiene Ciclovía":

\begin{abstract}
A minha geração foi criada nas ruas e pensamos: como recuperar esses lugares? A cidade de Bogotá tem mais de 5000 parques, mas por mais parques que tenhamos não se alcança os oito milhões de habitantes em política pública para fruição desses lugares. Criamos horários específicos para apropriação desses espaços passando a cuidá-los e valorizá-los. Como qualquer capital do mundo, há congestionamentos de veículos motorizados e percebemos que os ciclistas de finais de semana não pedalam nos dias da semana, assim, traçamos estratégias para incentivarem a pedalar nos deslocamentos diários para o trabalho, universidade e encontros sociais.
\end{abstract}

Maurício Martinez compreende que o êxito e a manutenção do Programa Ciclovía seguem graus de consolidação, ou seja, de finalidade recreativa e lazer para o uso cotidiano da bicicleta na cidade:

\begin{abstract}
Destaque para as ciclorrutas de Bogotá formadas por mais de 400 quilômetros de caminhos exclusivos, além do empréstimo de bicicletas registradas em diversos pontos da cidade como parte da conexão com o transporte público Transmilenio, são mais de três mil empréstimos diários, tornando-se uma alternativa promotora de segurança no trânsito, fazendo com que as pessoas sintam vontade de pedalar próximo ao lugar de destino. Com mais de 800.000 deslocamentos diários, estimulamos os ciclistas com campanhas informativas de conscientização no trânsito e entrega de brindes como caramañolas e capacetes, inclusive comparado ao transporte público no desestimulo ao uso do automóvel particular.
\end{abstract}

Em relação à infraestrutura cicloviária, tem ocorrido a atualização normativa periódica da política pública: em 1995, o "Plan de Desarrollo Formar Ciudad" (ALCADÍA MAYOR DE BOGOTÁ, 1995); em 1998, o "Plan Maestro de Ciclorrutas" (ALCADÍA MAYOR DE BOGOTÁ, 1998) e; em 2016, o "Plan de Desarrollo 
Económico, Social, Ambiental y de Obras Públicas" (ALCADÍA MAYOR DE BOGOTÁ, 2016).

Maurício Martinez esclarece a diferença entre "ciclovia", "ciclorruta" e "bicicarriles":

Prefeitos e promotores vindos do Brasil visitam nossa cidade que está em um grande impulso no tema ciclovía/ciclorrutas, porém, ressaltamos a diferença entre ciclovía - via fechada para veículos motorizados em um horário específico aos finais de semana e dias festivos, ciclorruta - via permanente para ciclistas e bicicarriles - corredores exclusivos retirados da rua próximos às estações públicas de empréstimo de bicicletas recreativas.

Um dos principais momentos vividos no cargo de coordenador-geral do Programa Ciclovía foi em 2006 com o evento "Relanzamiento de la Ciclovía" considerado uma nova etapa com a integração dos serviços de módulos de venda de alimentos e artigos esportivos, "ciclotalleres" (espaços para auxílio na mecânica de bicicleta), pontos de assessoria para atividade física, estações infantis, dentre outros (ALCADÍA MAYOR DE BOGOTÁ, 2014). Para Maurício Martinez, esta ação administrativa possibilitou a regulação formal do comércio e da publicidade, o que gerou uma forma de economia popular:

Um ponto positivo do Programa Ciclovía foi a geração de 700 postos de
trabalho, dando aproveitamento econômico e social para a via pública, além
de uma oportunidade para venda de produtos e serviços. Cabe ressaltar o
valor autogestão porque no começo, ambulantes vendiam bebidas alcoólicas
e refrigerantes sem controle e regulamentação governamental. Criamos um
desenho de gestão a partir da tienda de venta na rede de ciclovias
estabelecendo nichos de trabalho para as famílias organizadas por módulos
via contrato de cota simbólica mínima de dois mil pesos por jornada, ou seja,
menos de um dólar por dia. Esta regulamentação foi necessária para o
cuidado do posto de trabalho e, para manutenção, estabelecemos parcerias de
capacitação profissional sobre normas vigentes de manipulação de alimentos
e, além disso, o dinheiro da publicidade veiculada é revertido para
sustentação das atividades.

De acordo com a Secretaría de Cultura, Recreación y Deporte referente ao consumo semanal, foi constatado que $8 \%$ dos usuários acima de treze anos consumiram algum tipo de produto ou serviço, o que multiplicado por 52 semanas/ano, resulta a cifra média de 190 bilhões de pesos colombianos, embora apenas parte do montante proceda das vendas populares (CÁMARA DE COMERCIO DE BOGOTÁ, 2009).

Em 2005, foi realizada a " 1 a Conferência Internacional sobre Ciclovias Recreativas", iniciativa de diversos promotores de cidades latino-americanas gerando a Red de Ciclovías Recreativas de las Américas (RED CRA, 2019):

O Programa ciclovía alcançou nível de referência internacional em política pública urbana e, com isso, expandimos a organização para capacitações em outras regiões do país na realização de seminários. Desse contexto, criamos a Red Interamericana de Ciclovías que, atualmente conta com 57 organizações do continente americano que promovem o uso da bicicleta. Do encontro no ano de 2005, o resultado foi a assinatura da Declaracíon de Bogotá por 16 institutos promotores de ciclovias recreativas com o nome de Ciclovías Recreativas de las Américas.

Em visitas a outras localidades, Maurício Martinez exalta o diferencial do Programa Ciclovía que, ao envolver diversas regiões da metrópole, visibiliza a 
diversidade, ao contrário de "[...] outras cidades, o formato das ciclovias é de circuito, diferente da nossa proposta que interliga sítios turísticos-arquitetônicos com diferentes aspectos culturais para estimular as pessoas a conhecerem o espaço urbano". Se por um lado, o Programa Ciclovía executa diversas ações para a promoção do ciclismo urbano, por outro, a ação dos 24 coletivos cicloativistas (CIVICO, 2015) espalhados pelas diversas localidades da metrópole, estão caracterizados como encontros semanais noturnos que reúnem centenas de ciclistas por passeio, ocupando as vias públicas inspirados no movimento Critical Mass (CARLSSON, 2014). São exemplos de como o uso da bicicleta está arraigado na cultura cidadã bogotana.

Maurício Martinez destaca a atuação dos coletivos:

O começo da experiência foi traumática devido aos ciclopasseios ligados aos coletivos. O que são coletivos? São grupos de pessoas que se encontram para pedalar gerando um ambiente agradável e agregador. A cidade está dividida em 20 localidades e o objetivo do Programa é que cada localidade tenha seu coletivo. Algumas localidades têm três a quatro coletivos que, de tão frequentes, a Secretaria de Transito buscou a regularização porque muitos não respeitam as leis de trânsito e como estes ciclopasseios ocorrem no período noturno, a maioria dos ciclistas não utilizam capacetes e luzes refletivas. Isso é um conflito porque os coletivos são regidos por estímulos, assim exigimos que cumpram a sinalização de trânsito, o que torna um processo político complexo com a necessidade de respaldo dos governantes em vista de que os proprietários de veículos motorizados sentem que estão sendo incomodados.

Além do ciclismo recreativo e utilitário, os "escarabajos", ciclistas profissionais presentes nas competições internacionais, fomentam um ambiente que potencializa novos usuários de bicicletas (MONTEZUMA, 2011). Por outro lado, dos mais de 1900 bairros espalhados nas 20 localidades de Bogotá, a realidade conflituosa entre ciclistas e motoristas evidencia a dificuldade em organizar o compartilhamento viário:

\footnotetext{
Esta insatisfação ocorre porque as vias urbanas foram construídas para o transporte motorizado e os motoristas não admitem que o poder público feche a via para bicicletas. São dois motivos de discórdias, tanto destas pessoas incomodadas estarem em contato direto com os políticos, como dos comerciantes que pensam no fechamento das vias como déficit de consumo em seus estabelecimentos. Para resolver esse problema, traçamos estratégias com alternativas para agregar o comércio e, com isso, percebemos que a modificação viária e divulgação adequada, favorece o apoio dos governantes para a promoção do Programa Ciclovía.
}

Além das atividades habituais da ciclovia recreativa, o IDRD investe na "Escuela de la Bicicleta" para conduzir crianças, jovens e adultos ao uso da bicicleta com foco nas habilidades, destrezas básicas e normas de segurança com as atividades sendo realizadas no Sistema Distrital de Parques com a presença de promotores nos processos de ensino-aprendizagem (ALCADÍA MAYOR DE BOGOTA, 2019d). Outra iniciativa é o Programa "Al Colegio em bici" para promoção da bicicleta em ambiente escolar (ALCADÍA MAYOR DE BOGOTÁ, 2012):

O Programa de Mobilidade Escolar denominado Al colegio en bici reúne onze instituições distritais para difundir a compreensão na escola do uso da bicicleta nas ruas na cidade. Atualmente, são mais de oito mil crianças pedalando o trajeto "casa - colégio - casa" onde esperamos que sejam exemplos, seja para futuras gerações, como para influenciar os familiares a pedalarem. Além disso, estabelecemos uma parceria com a Secretaria de 
Educação na criação de manuais educativos sobre mobilidade e contratamos professores para capacitação com duração de 80 horas com conteúdo voltado para aprendizado a pedalar e regras básicas de comportamento no trânsito.

Dentre as várias formas de comunicação empregadas pelo IDRD, destaque para a "Semana de la Bicicleta" com a exposição e venda de equipamentos proporcionando aos empreendedores a mostra de seus produtos, variadas competições e mostra de bicicletas antigas com o espaço convertido em um enorme parque de atividades (ALCADÍA MAYOR DE BOGOTÁ, 2019e). Quanto aos benefícios para o sistema público de saúde, foi constatado que para cada dólar investido no Programa Ciclovía, triplica-se a inversão de investimentos com uma economia anual de 13 milhões de dólares (SARMIENTO et al., 2010) com efeitos para a saúde coletiva:

\begin{abstract}
A Organização Mundial da Saúde (OMS) recomenda aos adultos o mínimo de 120 minutos de atividade física por semana. Nossos estudos indicam a média de três horas na ciclovia cumprindo a recomendação estabelecida, porém, incentivamos as pessoas a pedalarem também durante a semana. Na questão ambiental, o problema está na emissão de dióxido de carbono pelo transporte motorizado. Além disso, os benefícios para o corpo humano são evidentes para o sistema cardiovascular e destreza funcional percebidos durante a convivência com companheiros de trabalho, pois aquelas pessoas que tinham o hábito de pedalar frequentemente sentem-se menos estressadas e felizes.
\end{abstract}

Em um primeiro momento, o Programa Ciclovía por meio das políticas de lazer, tem a finalidade de governar a população vinculando-a em torno de uma prática saudável, reduzindo assim os custos do Estado em termos da atenção em saúde. Para Rodríguez-Cortéz (2017) esta forma de governamentalidade neoliberal tem na publicidade, uma ferramenta de gerenciamento dos sujeitos para que se encarreguem de sua própria imagem corporal aprendendo a se venderem como ativos e saudáveis, por exemplo, sendo ecológicos utilizando a bicicleta cotidianamente, ou seja, o Programa Ciclovía como uma tecnologia de governo está estruturado a partir de uma rede de subjetivações que exercem um poder pastoral em um espaço público recreativo que, ao manter ordens disciplinares, sua arte de conduzir a conduta dos indivíduos está situada numa pedagógica que ensina normas de comportamento para serem bons cidadãos.

\title{
CONSIDERAÇÕES FINAIS
}

Esta pesquisa demonstra a atualidade temática do ciclismo urbano como estratégia analítico-discursiva contemporaneamente adequada às cartas internacionais de compromisso da Organização Mundial da Saúde (OMS) com a saúde coletiva (WHO, 2013). Especialmente em Bogotá, entendemos haver um complexo de relações entre poder e saber no território do Programa Ciclovía para formação de um ambiente social fornecedor de normas vitais cujas regras de comportamento são recomendadas pela OMS para uma vida saudável. Certamente, a ciclovia recreativa foi constituída para manutenção de ordens disciplinares, mas, por sua vez, sua arte de governar transformase em uma pedagogia voltada para conduzir os indivíduos ao governo de si, ou seja, o sujeito governado volta-se para o cuidado como empreendimento que valoriza seu próprio capital humano (RODRÍGUEZ-CORTÉZ, 2017).

No processo de implantação das ciclovias recreativas em Bogotá, percebemos a tônica da participação social na construção do Programa Ciclovía como uma política 
pública de Estado atuante junto à organização institucional do IDRD, o que nos demonstra a equidade na prática do ciclismo urbano como elemento fundamental na articulação institucional para a promoção da saúde e prevenção de doenças crônicodegenerativas como uma emergência instituída entre políticas de vida ativa e ambiente seguro que, diante do atual modelo de urbanização dependente do transporte motorizado, gera benefícios imateriais às comunidades envolvidas.

Também diante do modelo biomédico que tende a influenciar o fazer científico das áreas correlatas das Ciências da Saúde - levamos em conta a dinâmica das práticas pedagógicas da Motricidade Humana aplicada à gestão desportiva municipal (FERNÁNDEZ; PAZOS-COUTO; AZA, 2016; PAZOS-COUTO; TRIGO, 2014), que promove diálogos interdisciplinares entre os colégios de conhecimento das Humanidades e Ciências da Vida (PUTTINI et al., 2016), ampliando a complexidade do conceito de saúde, também válido para o campo de conhecimento da Saúde Coletiva (MINAYO; DINIZ; GOMES, 2016). Isso nos faz remeter ao fenômeno ciclismo urbano quanto à idealização do Sistema Único de Saúde (SUS), diretriz que garante a saúde como um direito universal no Brasil (PAIM, 2008): contraposto à Educação Física, que tem sua indicação para recreação e esporte, o uso da bicicleta considerado uma prática de saúde de responsabilidade individual remetendo-se às iniciativas privadas das academias e clubes esportivos, constitui-se como um direito humano à mobilidade ativa (TRONCOSO et al. 2018).

Diante das considerações, afirmamos sobre a análise dessa entrevista que, ao situar interpretações fundamentadas em linha teórica de pensamento foucaultiano inseridas na interface entre as Ciências Humanas e a Saúde Coletiva, o ciclismo urbano torna-se uma estratégia de política pública de planejamento inovadora da cidade de Bogotá: trata-se de uma iniciativa que promove a recreação no espaço público atrelada ao planejamento territorial. Portanto, a articulação entre participação social, gestão da política pública e organização institucional transforma-se nos eixos estruturantes dos compromissos éticos para a governamentalidade neoliberal ao orientar os gestores interessados nos benefícios do uso da bicicleta em ciclovias recreativas estruturados em ações governamentais regidas pelos princípios da justiça social e da cidadania.

\section{REFERÊNCIAS}

ALCADÍA MAYOR DE BOGOTÁ. Instituto Distrital de Recreación y Deporte (IDRD). Bogotá: Secretaría de Cultura, Recreación y Deporte, 2019a.

ALCADÍA MAYOR DE BOGOTÁ. Programa Recreovía. Bogotá: Secretaría de Cultura, Recreación y Deporte, Instituto Distrital de Recreación y Deporte (IDRD), $2019 \mathrm{~b}$.

ALCADÍA MAYOR DE BOGOTÁ. Semana de la Bicicleta. Bogotá: Secretaría de Cultura, Recreación y Deporte, Instituto Distrital de Recreación y Deporte (IDRD), 2019c.

ALCADÍA MAYOR DE BOGOTÁ. Escuela de la Bicicleta. Bogotá: Secretaría de Cultura, Recreación y Deporte, Instituto Distrital de Recreación y Deporte (IDRD), 2019d.

ALCADÍA MAYOR DE BOGOTÁ. Servicio Social Estudiantil Ciclovía. Bogotá: Secretaría de Cultura, Recreación y Deporte, Instituto Distrital de Recreación y Deporte (IDRD), 2019e.

ALCADÍA MAYOR DE BOGOTÁ. Plan de Desarrollo Económico, Social, Ambiental y de Obras Públicas para Bogotá, D.C - 2016-2020. Acuerdo 645 de 2016. Bogotá: Departamento Administrativo de Planeación Distrital, 2016. 
ALCADÍA MAYOR DE BOGOTÁ. Encuesta de Movilidad 2015. Bogotá: Secretaria de Movilidad, 2015.

ALCADÍA MAYOR DE BOGOTÁ. El libro de la bici 2014. Bogotá: Secretaria de Cultura, Recreación y Deporte, Instituto Distrital de Recreación y Deporte (IDRD), 2014.

ALCADÍA MAYOR DE BOGOTÁ. Programa Al Colegio en Bici. Bogotá: Secretaría Distrital de Planeación. Dirección de Vías, Transporte y Servicios Públicos, 2012.

ALCADÍA MAYOR DE BOGOTÁ. Plan Maestro de Ciclo-Rutas. Bogotá: Instituto de Desarrollo Urbano. Bogotá: Departamento Administrativo de Planeación Distrital, 1998.

ALCADÍA MAYOR DE BOGOTÁ. Plan de Desarrollo Económico, Social y de Obras Públicas para Santa Fé de Bogotá D.C. - 1995-1998. Decreto n 295. Bogotá: Departamento Administrativo de Planeación Distrital, 1995.

ANDRADE, V.; RODRIGUES, J. M. Economia da Bicicleta no Brasil. Rio de Janeiro: LABMOBUFRJ e Aliança Bike, 2018.

BAUMANN, C.; BOJACÁ, M.; RAMBEAU, M.; WANNER, Z. Biciudades 2013: un estudio regional acerca del uso de la bicicleta como medio de transporte en América Latina y el Caribe. Ciudad de Mexico: Banco Interamericano de Desarrollo (BID), 2013.

BRASIL. Lei ${ }^{\circ} \mathbf{1 3 . 7 2 4}$ de 4 de outubro de 2018. Institui o Programa Bicicleta Brasil (PBB) para incentivar o uso da bicicleta visando à melhoria das condições de mobilidade urbana. Brasília: Presidência da República, 2018.

BRASIL. Caderno de Referência para Elaboração de Plano de Mobilidade Urbana (PlanMob). Brasília: Ministério das Cidades, Secretaria Nacional de Transporte e Mobilidade Urbana, 2015.

Brasil. Política Nacional de Promoção da Saúde. 3. ed. Brasília : Ministério da Saúde, 2010.

BRASIL. Lei no 12.587, de3 de janeiro de 2012. Institui as diretrizes da Política Nacional de Mobilidade Urbana. Brasília: Casa Civil, 2012a.

BRASIL. Resolução n. 466 do Conselho Nacional de Saúde (CNS). Brasília: Conselho Nacional de Saúde, 2012b.

BRASIL. Estatuto da Cidade. 3. ed. Brasília : Senado Federal, Subsecretaria de Edições Técnicas, 2008

CÁMARA DE COMERCIO DE BOGOTÁ. Movilidad en bicicleta en Bogotá. Bogotá: Cámara de Comercio de Bogotá, 2009.

CARLSSON, C. Nowtopia. Iniciativas que estão construindo o futuro hoje. Porto Alegre: Tomo Editorial, 2014.

CARVALHO, M. L.; FREITAS, C. M. Pedalando em busca de alternativas saudáveis e sustentáveis. Ciência \& Saúde Coletiva, v. 17, n. 6, p. 1617-1628, 2012.

CICLOCIDADE. A mobilidade ativa na cidade de São Paulo. São Paulo: Associação dos Ciclistas Urbanos de São Paulo, 2016.

CIVICO. ¡Péguese la rodadita! Bogotá pedalea en más de 20 colectivos urbanos de ciclistas. Civico.com, 28 oct. 2015.

DENZIN, N.; LINCOLN, I. Manual de investigación cualitativa. Métodos de recolección y análisis de datos. Barcelona: Gedisa Editorial, 2015.

ESTRADA, G. M.; SARMIENTO, O. L.; CASTILLO, A. D.; JACOBY, E.; PRATT, M.; TORRES, A.; SCHMID, T.; CAMACHO, A.; RAMOS, M.; RUIZ, O.; ALEMÁN, O. R.; PARDO C.; STIERLING, G. 
Manual para implementar y proporcionar la Ciclovía Recreativa. Cidade do México: Organización Panamericana de la Salud, 2009.

FAJERSZTAJN, L.; VERAS, M.; SALDIVA P. H. N. Como as cidades podem favorecer ou dificultar a promoção da saúde de seus moradores? Estudos Avançados, v. 30, n. 86, p. 7-27, 2016.

FERNÁNDEZ, J. E. R.; PAZOS-COUTO, J. M.; AZA, E. T. La gestión del deporte en clave educativa de Motricidad Humana. Retos. Nuevas Tendencias en Educación Física, Deporte y Recreación, v. 30, n. 2, p. 92-97, 2016.

FMB. Foro Mundial de la Bici. Disponível em: 〈http://www.fmb8.org/>. Acesso em: 06 out. 2018.

FOUCAULT, M. Segurança, território, população. São Paulo: Martins Fontes, 2008.

GODEFROOIJ, T.; PARDO, C.; SAGARIS, L. Cycling-inclusive Policy Development: a handbook. Utrecht: Interface for Cycling Expertise, 2009.

HARTOG, J. J.; BOOGAARD, H.; NIJLAND, H.; HOEK, G. Do the health benefits of cycling outweigh the risks? Ciência \& Saúde Coletiva, v. 16, n. 12, p. 4731-4744, 2011.

HENRY, M. Fenomenología de la vida. Buenos Aires: Prometeo Libros, 2010.

MCLEOD, K. Where We Ride: An Analysis of Bicycling in American Cities. American Community Survey Data Report. Washington: League of American Bicyclists (LAB), 2016.

MINAYO, M. C. S.; DINIZ, D.; GOMES, R. O artigo qualitativo em foco. Ciência \& Saúde Coletiva, v. 21 , p. 8 , p. 2326-2326, 2016.

MONTERO, S. Worlding Bogotá's Ciclovía. From Urban Experiment to International "Best Practice". Latin American Perspectives, v. 213, n. 44, p. 111-131, 2017.

MONTEZUMA, R. Ciudadanos, calles y ciudades: las Américas unidas por una Ciclovía. Bogotá: Organización Panamericana de la Salud (OPAS), 2011.

NEUN, M.; HAUBOLD, H. The EU Cycling Economy. Arguments for an integrated EU cycling policy. Bruxelas: European Cyclists Federation (ECF), 2016.

ONU. Sustainable Development Goals. 17 Goals to Transform our World. Genebra: United Nations (UN), 2016.

ONU. Conference of the Parties (COP-21). Paris: United Nations (UN), Twenty-first session, 30 November to 11 December 2015.204 Disponível <https://unfccc.int/resource/docs/2015/cop21/eng/109r01.pdf>. Acesso em: 04 abr. 2018.

PAHO. Regional Strategy and Plan of Action on an Integrated Approach to the Prevention and Control of Chronic Diseases. Washington: Pan American Health Organization, 2007.

PAIM, J. S. Reforma sanitária brasileira: contribuição para a compreensão e crítica. Salvador: EDUFBA; Rio de Janeiro: FIOCRUZ, 2008.

PARDO, C.; MALUF, A.; XAVIER, G. N. A.; HAGEN, J.; GOMEZ, J.; SILVA, J. C.; BREITHAUPT, M.; MAlateSTA-MEli, M. E. B.; TERRAMOTO, T.; DAGGERS, T.; SILVA, V. L. G. Ecomobilidade no Brasil - uma construção conjunta. Eschborn: GIZ - Deutsche Gesellschatf für Internationale Zusammenarbeit, Ministério Federal de Cooperação Econômica e do Desenvolvimento, 2011.

PAZOS-COUTO, J. M.; TRIGO, E. Motricidade humana y gestión municipal. Estudios Pedagógicos, v. 40, n. 1, p. 373-387, 2014. 
PUTTINI, R. F.; MANFIOLETE, L. Dri; JIMENEZ-MUÑOZ, J. A.; SILVA, C. S.; HIGA, C. L.; BERSI, R. M.; GUIMARÃES, A. B. F.. Humanities of the field of Human Motricity. Motricidade, v. 12, n. 3, p. 4-11, 2016.

RED CRA. Declaración de Bogotá. Bogotá: Red de Ciclovías Recreativas de las Américas, 2019.

RODRÍGUEZ-CORTÉZ, A. B. La ciclovia de la ciudad de Bogotá: espacio productor de subjetividades. 2017. Tese (Doctorado en Ciencias Sociales) - Universidad Externado de Colombia, Bogotá, 2017.

SARMIENTO, O. L.; TORRES, A.; JACOBY, E.; PRATT, M.; SCHMID, T.; STIERLING, G. The Ciclovía-Recreativa: A Mass-Recreational Program with Public Health Potential. Journal of Physical Activity and Health, v. 7, suppl. 2, p. S163-S180, 2010.

SPERANDIO, A. M. G.; FRANCISCO FILHO, L. L.; MATTOS, T. P. Política de promoção da saúde e planejamento urbano: articulações para o desenvolvimento da cidade saudável. Ciência \& Saúde Coletiva, v. 21, n. 6, p. 1931-1937, 2016.

TORRES, A.; SARMIENTO, O. L.; STAUBER, C.; ZARAMA, R. The Ciclovia and Cicloruta programs: promising interventions to promote physical activity and social capital in Bogotá, Colombia. American Journal Public Health, v. 103, n. 2, p. 23-30, 2013.

TRONCOSO, L. D. M.; PUTTINI, R. F.; GONÇALVES JUNIOR, L.; TORO-ARÉVALO, S. A. Ciclismo urbano como direito à mobilidade ativa na cidade de São Paulo. Movimento, v. 24, n. 3, p.1015-1028, 2018.

VAN MANNEN, M. Fenomenología de la práctica. Métodos de donación de sentido en la investigación y la escritura fenomenológica. Popayan: Ediciones Unicauca, 2016.

WHO. The top 10 causes of death. Geneva: World Health Organization - Notas Descriptivas, 24 mayo 2018. Disponível em: 〈http://www. who.int/es/news-room/fact-sheets/detail/the-top-10-causes-of-death>. Acesso em: 10 set. 2018.

WHO. The Helsinki Statement on Health in All Policies. The 8th Global Conference on Health Promotion. Geneva: World Health Organization, 2013. Disponível em: <http://www.who.int/healthpromotion/conferences/8gchp/en/>. Acesso em: 27 jul. 2018.

Recebido em: 01 jun. 2019.

Aprovado em: 27 ago. 2019. 